\title{
When the Sun Sets Over Suburbia: Class and Subculture in Bruce Beresford's Puberty Blues
}

Bruce Beresford's film Puberty Blues (1981) focuses on Australian surf culture of the 1970s

and the Sydney beach-side suburb of Cronulla Beach, presenting the Cronulla surf subculture as a prism through which Australian society is viewed. The film, which centres on the quest of the characters of Debbie and Sue to join the élite Greenhills surfing gang, signifies a turning point in Australian screen depictions of class, prefiguring an increased emphasis on the middle class and deviating from a traditional equation of class with the working class.

The film's bleak and satirical portrayal of the Australian middle class also reveals dimensions of suburban Australia that are usually absent from local films and television series. Based on Kathy Lette and Gabrielle Carey's 1979 novel of the same name, the film draws on a cultural tradition that associates surfing with freedom from social constraints. Yet the film depicts the protagonists' idealization of surfers as being undermined when drugs intrude upon their world. The flight from middle-class suburban existence also suggests that the comforts of suburbia are deceptive. This article's analysis of class and subculture in Puberty Blues aims to draw greater attention to Australian film depictions of subculture and middle-class life, for despite the large body of work around subcultures and although the majority of Australian films made in the last twenty-five years centre on the middle class, these aspects of Australian cinema have generally received little analysis from film and cultural studies scholars.

\section{Social landscapes and suburbia}

Puberty Blues has been identified with a cycle of Australian youth films that appeared during the late 1970s (Dermody \& Jacka, 1988, pp. 41-2; McFarlane, 1987, p. 44; Stratton, 1990, p. 
146; Ellis, 1981, p. unknown). The films in this cycle include The FJ Holden (Michael Thornhill, 1977), Mouth to Mouth (John Duigan, 1978) and Hard Knocks (Don McLennan, 1980). This cycle can be situated, in turn, within what Meaghan Morris has dubbed the 'Australian 'social landscape' tradition' (1989, p. 132). Like The FJ Holden, Puberty Blues focuses on a social environment in which male characters' bonds with males and their cars are privileged. For instance, both Puberty Blues and The FJ Holden include scenes in which young men use cars as locations for sexual encounters. Yet Puberty Blues, unlike Thornhill's film, emphasizes female perspectives. Beresford's film has in common with Hard Knocks and Mouth to Mouth a focus on girls whose quests for experience and advancement lead to problematic sexual relationships and delinquency. Although all of these films share a primarily Anglo-Australian perspective, the focus on working-class characters in The FJ Holden, Mouth to Mouth and Hard Knocks can be contrasted with Puberty Blues' emphasis on the middle class.

Puberty Blues foreshadows a proliferation of later films and television series that centre on the Australian middle class. In subsequent decades, a general emphasis on the middle class has become evident in Australian films, including those about teenagers and youth adults. This trend is exemplified by such films as The Big Steal (Nadia Tass, 1990), Muriel's Wedding (P. J. Hogan, 1994), Me Myself I (Pip Karmel, 1999) and Dating the Enemy (Megan Simpson Huberman, 1996). It additionally includes The Wogboy (Aleksi Vellis, 2000) and Looking for Alibrandi (Kate Woods, 2000), which foreground ethnic groups that are only peripherally evident in Puberty Blues. Beresford's film also prefigures the inception of prominent Australian television series that centre on youthful characters and suburban locales. Like Puberty Blues, the soap opera Neighbours emphasizes the domestic troubles of affluent, predominantly Anglo-Australian suburbanites. Equally, Home and Away echoes 
Beresford's film in being promoted on the basis of its coastal setting and youthful cast. The film's foreshadowing of a middle-class dominance of Australian screen culture may be linked to Puberty Blues' association with increased local production of market-driven films (Dermody \& Jacka, 1988, p. 151) and to a recognition that the majority of cinemagoers are middle-class.

Yet Puberty Blues' references to class difference, drug use and sexual abuse distinguish this film from long-running Australian soap operas, in which such themes rarely, if ever, involve the central characters. Beresford's film's tackling of disturbing themes is exemplified by a sequence in which three male characters, including the protagonist's former boyfriend, manipulate a girl into having sex with them in succession. It is probably on the basis of such episodes that Germaine Greer sees in Puberty Blues a more honest, unidealised view of the seaside suburbs that Australian soap operas have since 'sold ... to the British public as a kind of working-class Paradise' (2002, p. xii). The film's portrayal of sex and gender relationships shares with other Australian 'sexual mores' films (such as Bruce Beresford's Don's Party [1976]) an ‘exposé quality' (Dermody \& Jacka, 1988, p. 57) and has a satirical tendency to relish the violation of social constraints upon hedonistic behavior. Indeed, Puberty Blues' juxtapositioning of unfettered hedonism with a bleak view of human relationships is easily reconciled with Meaghan Morris' account of 1970s Australian cinema:

An unforgiving soul watching [these] raunchy comedies and realist dramas might be forgiven for concluding that Australia is dominated either by a race of unattractively puritan adolescents obsessed with "getting it" ..., or by a race of misogynist psychotics for whom sexuality ... is a danger zone, with hatred, fear and contempt ever-present and prone to erupt into violence. $\left(1980\right.$, p. 134) ${ }^{1}$ 
While prefiguring Australian screen culture's emphasis on middle-class suburbia, Puberty

Blues also presents a more confrontational view of this world than do many subsequent Australian films and television series.

Yet a proliferation of middle-class subjects does not necessarily entail an emphasis on class themes. In fact, Puberty Blues appeared at the start of what Tom O'Regan describes as a 'partial decline ... of class-based emphases' in Australian screen culture (O’Regan, 1996, p. 269) and the film's depiction of the middle class has received little attention from film critics or scholars. O'Regan attributes Australian film's reduced emphasis on class to the emergence of 'alternative problematizations of social life and national lifeways' that place greater emphasis on 'gender, ethnic and indigenous issues' (1996, p. 269). In this light, 'the 'traditional' Anglo male working-class culture [may be considered] oppressive, misogynist and prejudiced' (O'Regan, 1996, p. 269). In recognition of this shift in values, Puberty Blues' focus on girls' experiences of the surfing subculture has been linked to the widespread influence of second wave feminism (Speed, 2004, pp. 54-60). Yet despite other configurations of social difference, Puberty Blues does allude to class themes. For instance, the film's use of long shots positions the protagonists' lives within a wide spatial realm, thereby imbuing the film with an implicit social dimension. In a scene in which the gang is housebound by rain, for instance, an ironic relationship is established between the surfers and middle-class suburbia. Framed in a long shot of one gang member's elegant family home, the surfers' crude consumption of a cake highlights their social ineptitude in relation to their pristine surroundings. Puberty Blues' cinematographic breadth and use of irony thus alludes to the social context of the characters' lives. 
Beresford's film also draws on the novel's portrayal of the Cronulla social hierarchy. In particular, the use of a middle-class, first person narrator in Lette and Carey's novel positions Cronulla as a locus of conflict between local surfers and working-class youths, who gravitate to the area from Sydney's west:

Each ... surfing gang ... resents the intrusion of any other tribe on to their beach. Cronulla surfies wage an endless war against the kids who come from the Western Suburbs. They're called Bankies, Towners or Billies. Cronulla being at the end of the train line, all sorts of tattooed, greasy, bad-surfing undesirables slide off. Boys from Cronulla are just as unwelcome on other beaches. (Lette \& Carey, 2002, p. 31) In Class in Australia, Craig McGregor positions this novel as a key expression of the "class hostility' that can erupt when people venture for recreational purposes into terrain occupied by another social group (1997, pp. 187-8). He notes that the novel represents the perspectives of middle-class Cronulla teenagers with 'parents who went to Europe on holiday.' (McGregor, 1997, p. 188). Without explicitly highlighting any particular class, the novel conveys in colloquial terms the middle-class narrator's distaste for working-class interlopers.

Beresford's film expands visually upon the novel's delineation of this social viewpoint, with the novel's hierarchical view of 1970s Cronulla being rendered spatially in the film. For instance, the first scene's introduction to this world employs in voiceover narration lifted from the novel:

There were three main sections of Cronulla Beach - South Cronulla, North Cronulla and Greenhills. Everyone was trying to make it to Greenhills. That was where the top surfie gang hung out - the prettiest girls from school and the best surfies on the beach. The bad surfboard riders on their 'L' plates, the Italian family groups and the 'uncool' 
kids from Bankstown swarmed to South Cronulla - Dickheadland. That's where it all began. We were dickheads.

The scene's positioning of the protagonists, Debbie and Sue, in relation to their surroundings reinforces the film's emphasis on the perspectives of upwardly-mobile locals. For instance, the girls' disdain for South Cronulla and determination to 'make it' to Greenhills is conveyed through mobile shots that follow their movement through and beyond the crowds. The film's focus on middle-class Anglo-Australians is also conveyed through the narrator's casual marginalization of immigrants and the working class. The allusion to the presence of Italians is barely reinforced by the accompanying images, in which the sea of white bodies is only once broken by a glimpse of a Mediterranean complexion. Equally, the noted exclusivity of Greenhills is evident in the sparse occupancy of the latter beach, where the protagonists seat themselves. Although a subsequent scene provides an aerial overview of the various Cronulla beaches, the opening sequence's closer framing of Debbie and Sue privileges their perspectives of the beach hierarchy that defines their quest to become top 'surfie chicks' (Lette \& Carey, 2002, p. 1). From its first scene, the film's perspective of Cronulla underscores the protagonists' middle-class identities.

Puberty Blues forms a link between 1970s social realist films, with their focus on workingclass themes, and Australian screen culture's shift of emphasis to the middle class, retaining a frankness in the depiction of sexual relationships that is often absent from subsequent depictions of the middle class. Beresford's film also renders in spatial terms the novel's hierarchical view of 1970s Cronulla. [+ a sentence deleted here] 


\section{Surfing and social climbing}

The film of Puberty Blues is embedded in mythologies surrounding the Australian beach and surfing. Although part of nature, the beach has long been linked to culture. For instance, the 'figure of the bronzed lifesaver' is an emblem of modern Australian identity and some commentators literally equate Australia with the beach (Fiske, Hodge \& Turner, 1987, pp. 53-4). Yet the beach is also imbued with diverse meanings. For instance, John Fiske, Bob Hodge and Graeme Turner identify two ‘apparently contradictory’ paradigms in which Australian beaches are situated: 'one places it within the category of the environment of the city, making it intrinsic to ... "culture"; the other sees it in the category of the "natural", the alternative ... to the comfortable security of the suburb.' (1987, p. 55) With surf beaches such as Greenhills perceived to embody 'nature at its most uncompromising', surfing is imbued with connotations of defiance, youth, hedonism and freedom from social constraints (Fiske, Hodge \& Turner, 1987, pp. 66-7). The surfer is thus fundamentally opposed to the lifesaver's association with responsibility and community spirit (Fiske, Hodge \& Turner, 1987, pp. 5567). As Fiske, Hodge and Turner note, even the advertising industry's appropriation of the image of the surfer has scarcely diminished the perception that the subculture occupies a ‘romantic position' outside the social hierarchy (1987, pp. 66-7). In Puberty Blues, the protagonists' world view is dominated by their idealization of surfers and surfing.

The girls' preoccupation with the surfing gang partly obscures the film's emphasis on middle-class youth. For Debbie and Sue, membership of the Greenhills gang overrides all other social distinctions. To the extent that the film sympathizes with Debbie and Sue's quest to avoid exclusion, Puberty Blues subordinates class to subculture, a group of people with 
something in common that distinguishes them from other social groups and from a community or culture (Thornton, 1997, pp. 1-4). The film's displacement of class echoes Phil Cohen's assertion that subcultures serve to 'express and resolve' generational conflicts through 'decant[ing] ... tensions which appear face-to-face in the family and ... replac[ing] them [with] a generational-specific symbolic system.' (1997, p. 94) The privileging of subculture in Puberty Blues is implicit in the Greenhills gang's inclusion of young people of working-class backgrounds.

However, the disjunction between subcultural values and the larger class system is highlighted in the film's portrayal of Debbie's first boyfriend, a working-class surfer named Bruce. A contrast is established between Bruce and her parents' middle-class values in a scene in which he visits Debbie and her family. Bruce's class origins are accentuated when he caresses the wallpaper of Debbie's spacious home and makes profane observations, such as 'Christ, your old man must be loaded!' The class contrast is developed to a comic climax when Bruce takes tea with the Vickers and presumptuously asks to 'bludge' a cigarette from Debbie's father. He also admits candidly that he's 'not too bloody interested' in working and would 'rather surf'. Here, Debbie's apparent obliviousness to her parents' disapproval reflects the subculture's tendency to obfuscate larger social differences. A capacity for markers of subcultural identity to coincide with, and thereby conceal, manifestations of class is exemplified by Bruce's panel van, a vehicle favoured by surfers and also by blue-collar workers. Indeed, Fiske, Hodge and Turner view the panel van as an 'anomalous' object, in that it simultaneously evokes the contradictory entities of work and leisure, mass production and individualization, youth and adulthood, art and disposability (1987, pp. 67-8). Debbie's decision to become Bruce's girlfriend is symptomatic of a privileging of subculture over class-related factors such as socio-economic level, employment prospects and education. 
The protagonists' fascination with surfers and surfing suggests a fetishisation of a subcultural identity that seems to offer escape from their existing social lives. For instance, the scene of the girls' first encounter with the surfers can be read in relation to Laura Mulvey's model of cinematic spectatorship, in which the 'woman is displayed as sexual object' and the male character is 'bearer of the look of the spectator' (1989, pp. 19-20). 'Look at Danny', Sue tells Debbie in the first scene, and both girls fall silent while they watch Danny, a Greenhills gang member, surf. In this reversal of Mulvey's theory, the surfer is a spectacle seen from the female protagonists' subjective point of view. This and several other scenes engage in a fetishisation of the surfer as 'a perfect product, whose body ... is the content of the film and the direct recipient of the spectator's look' (Mulvey, 1989, p. 22). In this way, the film tends to associate surfing with the realm of fantasy, as distinct from the realm of social relationships. It is in such situations that Debbie and Sue appear to fulfill their quest to escape their former identities of 'dickheads'. Yet the ideal seen in Puberty Blues' fetishisation of the surfer is underpinned by the girls' subcultural ambitions. The film's positioning of the surfing gang as a source of fantasies of escape is thus fundamentally inseparable from the larger social order.

The fetishisation of the surfer is intrinsic to the protagonists' idealization of the Greenhills gang as a social entity. In Puberty Blues, Debbie and Sue equate the Greenhills gang with that which they perceive to be lacking in their lives. Indeed, the manner in which the protagonists first apprehend Danny is neither gender-specific nor particular to surfing. For instance, it is echoed in their response to one of the Greenhills girls, Cheryl, when she rides a horse onto the beach. Yet surfing is the main source of mastery and privileged freedom in Puberty Blues. The privileging of the surfer as a social entity is particularly evident in scenes that present 
surfing as a substitute for social relationships. For instance, a later sequence shows the Greenhills girls suspending all interaction to sunbathe while their boyfriends surf. In this way, the film portrays surfing as an implicit source of exemption from social responsibility. Inherent to this exemption is the fact that surfing is an almost exclusively male activity in Puberty Blues, where male characters' avoidance of emotional engagement is often simply accepted by their girlfriends. This privileging of surfers is fuelled by subculture's 'innately oppositional' relationship to the values of the larger society (Thornton, 1997, p. 2). As Sarah Thornton notes, subcultures 'appear to bring a little disorder to the security of neighborhood' (1997, p. 2). Debbie and Sue's infatuation with surfers and surfing suggests an instinctive attraction to surfers' defiance of social constraints and embrace of anti-authoritarian attitudes.

Yet the protagonists' quest to join the Greenhills gang reflects an acute awareness in principle of the workings of a larger social hierarchy. In one scene, for instance, Debbie and Sue are shown attempting to ingratiate themselves with one of the Greenhills girls, Tracey. Here, a comic contrast emerges between Tracey's resolutely scornful attitude and the protagonists' transparent attempts at flattery:

Sue: Gee, your hair looks great today, Trace.

Debbie: Yeah, unreal. Got a cigarette, Trace?

Tracey: Yeah - but you're not getting any!

In conjunction with the hierarchical implications of this exchange, Debbie's first-person narration serves as a virtual textbook on subcultural membership, laying bare the rules on joining the Greenhills gang: 'If you wanted to get into the gang, you had to crawl after and suck up to all the gang girls'. This dimension of Puberty Blues is reinforced by the swiftness of the protagonists' transition to become Greenhills girls. For instance, the film presents Debbie and Sue's transformation from social outcasts to Greenhills girls as occurring within a 
single school day, commencing with a brawl between Debbie and a gang member, Cheryl, and ending with Debbie and Sue's participation in an illicit smoking session. Although the protagonists seem unaware of class difference within the Greenhills gang, their endurance of the gang's initiation rites is strongly redolent of upward social mobility.

Puberty Blues' partial mystification of class is symptomatic of the extent of class awareness among many Australians, paralleling the frequent absence of class themes from popular Australian and American culture since the 1970s. In Australian film, television and popular understanding, class difference is often underestimated, unrecognised or unacknowledged. As in the United States, the absence of 'a convenient system of inherited titles, ranks, and honors' means that class privilege is often displaced onto consumable items such as styles of clothing, cars and household accessories (Fussell, 1983, p. 18). In this context, Paul Fussell has argued, a citizen 'can be puzzled about where, in the society, he stands. [sic]' (1983, pp. 18-19). It is perhaps symptomatic of a lack of sustained consideration of class that more than half the Australian population identifies itself as middle class (McGregor, 1997, p. 162). According to John Fiske, the failure to acknowledge class distinctions is itself class-specific: 'Australia is, in its own imagining, a classless (ie. Middle class) society.' (1983, p. 128) In this context, the surfing subculture of Puberty Blues serves as a relatively apolitical prism through which class in Australian society can be viewed. The film is therefore pivotal to examining popular understandings of the Australian class system.

The film's displacement of class awareness onto subcultural distinctions can be considered in the context of what Tom O'Regan refers to as the 'othering of the Australian' (1996, p. 250). Drawing on the work of Tim Rowse, O'Regan argues that Puberty Blues 'ask[s] ... its audience to play anthropologist to their culture' (O'Regan, 1996, p. 250). The film 
exemplifies a tendency for Australian films to 'establish ... relations of alterity between the audience and what is on-screen.' (O'Regan, 1996, p. 250) Puberty Blues invites the audience to 'play anthropologist' to Australian culture in two ways. On the one hand, the surfing subculture is seen satirically from both within and without, through Debbie and Sue's calculated quest to join the Greenhills gang. On the other hand, and less obviously, the surfing gang's superficial eschewal of larger social power relationships informs the film's satirical portrayal of the middle class, Debbie and Sue's alienation from their parents' world implying a detached perspective of the larger Cronulla society. Although the film's depiction of class is largely external to the girls' perspectives, Puberty Blues illuminates the differential hierarchies of the surfing subculture and middle-class suburbia.

For Debbie and Sue in Puberty Blues, membership of the top surfing gang overrides any particular class identity. At the same time, the film draws attention to the disparity between the protagonists' perspectives and the greater diversity of Cronulla beach society. Yet, despite surfing's ethos of anti-authoritarianism and hedonistic freedom, the surfing gang in Puberty Blues provides no escape from the conservatism and upward mobility of the middle class.

\section{Subculture and middle-class youth}

Beresford's film shares with the Australian social landscape films of the 1970s a tendency to foreground the social circumscription of characters' lives. The film's relationship to this tradition can be elaborated with reference to Meaghan Morris's argument that The FJ Holden presents a 'gendered spatial determinism' (1989, p. 126). In The FJ Holden, the protagonist's attachment to his car is associated with a sense of freedom that is ultimately revealed to be limited (Morris, 1989, p. 126). 'In spite of the car's promise of wildness and freedom,' 
Morris notes, 'the working-class suburbia of The FJ Holden is a totally ordered environment: its spaces are so circumscribed, and its social dynamic so circular, that the 'hero's' trajectory is a dead-end drive.' (italics in original) (1989, p. 126) Equally, in Puberty Blues the surfing gang offers only an ostensible alternative to suburban, middle-class existence. The social landscape film's emphasis on the circumscription of young working-class lives extends in Puberty Blues to the representation of the middle class.

Just as Bruce's visit prompts the Vickers to brand him unsuitable for their daughter, Beresford's film presents the actions of middle-class young people as being constrained by social forces. For instance, a subplot in Puberty Blues links the middle-class upbringing of Debbie's second boyfriend, Garry, to his ultimately fatal drug use. In particular, Garry's escalating use of heroin coincides with his struggle to fulfill his parents' aspiration for him to follow his father into dentistry. Garry's social and psychological constriction becomes evident in a scene in which Debbie visits him to discuss her suspected pregnancy. Here, the oppressiveness of his parents' diligence is suggested when his mother's delivery of a tea tray to his bedroom door coincides with an angry discussion between her son and Debbie. Given Garry's drugged state, the sequence not only highlights his mother's ineffectuality but also implies that his crisis is compounded by parental incomprehension. The scene's ironic portrayal of the comforts of middle-class life is also indicative of a tendency for Puberty Blues, like many teen films, to characterise the main characters' parents as little more than stereotypes. For Garry, as for Bruce, middle-class notions of propriety are obstacles to attaining the freedom and autonomy that surfing seems to promise.

The significance of Puberty Blues' depiction of middle-class youth is associated with changing perceptions of the middle class. Whereas discussions of class in Australia once 
focused almost exclusively on the working class, the growing perception of the middle class as 'a universal class, a class which is everywhere represented as representing everyone' calls for attention to its actual status as 'a distinct class' (Ehrenreich, 1990, pp. 4-5). Additionally, and at odds with Australia's purportedly middle-class majority, Puberty Blues appeared at the beginning of a decade in which the security of the middle class could no longer be taken for granted. Since the late 1980s, growing inequality in the social distribution of wealth has resulted in some middle-class Australians being 'hit' for the first time 'by the same maladies and problems which ... they assumed ... afflicted only the working class: unemployment, lower living standards, fear of the sack, a ... struggle to make ends meet.' (McGregor, 1997, p. 162) Viewed today, Puberty Blues' portrayal of Garry's struggle against his parents' expectations seems even more poignant in light of society's increasing emphasis on the relationship between adolescent accomplishment and an adult middle-class lifestyle. Puberty Blues' focus on middle-class residents of Cronulla, which has since 'climbed even further up the real estate scale' (McGregor, 1997, p. 188), is accentuated by a growing recognition that the Australian middle class is less secure than was once thought.

The film implies that the surfing subculture serves for Garry as a fleeting alternative to his family life. This is particularly evident in the idyllic tone of an episode in which he and Debbie spend the night at an abandoned holiday house. Whereas the earlier sex scenes between Debbie and Bruce highlight the emotional vacuity of their interaction, the encounter between Garry and Debbie is presented as more meaningful through occurring off screen. Equally, Debbie and Garry's light-hearted banter in bed the next morning positions the encounter as a source of happiness. Yet the precariousness of this bliss is suggested by the couple's derelict surroundings and underscored by Garry's repeated references to his drug use. Debbie's subsequent fear that her unwanted pregnancy occurred in this encounter throws 
into full relief the fragility of their happiness. In Beresford's Puberty Blues, the precariousness of Garry's contentment with Debbie highlights his ultimate lack of hope.

The intrusion of drugs into the surfing gang exposes the association between surfing and social freedom as illusory. In particular, the film positions the drug element of the surfing subculture as having a capacity to foreclose adolescence, a 'latency period' (Erikson, 1974, p. 156) that has traditionally enabled middle-class youth to experiment without full responsibility for their actions. Whereas adolescence is intended to assist in the formation of an adult social identity (Erikson, 1974, pp. 155-6), Garry's decline into drug abuse and death effectively eludes this means of social control. Indeed, his use of drugs in an apparent attempt to avoid dealing with his parents' expectations echoes Phil Cohen's account of the options faced by some working-class youth:

For the kids who are caught up in the internal contradictions of a subculture, what begins as a break in the continuum of social control can $\ldots$ become a permanent hiatus in their lives. Although there is a certain amount of ... mobility [between subcultures], there are no career prospects! There are two possible solutions: one leads out of subculture into early marriage ... ; alternatively, subcultural affiliation can provide a way into membership of one of the deviant groups which exist in the margins of subculture and often adopt its protective coloration ... (such groups as pushers, petty criminals, junkies, even homosexuals). (1997, p. 96)

Despite his middle-class origins, Garry's fate echoes this description of working-class youth. Although he shares with the gang a liking for marijuana and confides in other surfers his desire to use heroin, the inconspicuousness of Garry's drift from surfing into addiction becomes evident when Debbie's inquiry after him prompts no explanation from the surfers. She is told merely that 'he doesn't surf much anymore'. In Puberty Blues, the surfing 
subculture's tendency to privilege instant physical gratification over a progression to adulthood underpins the circumscription of middle-class existence.

By contrast, Debbie and Sue's ultimate defiance of the Greenhills gang suggests a quest for an alternative to the gang, although not an alternative to subcultural or middle-class identity. Given emphasis through screenwriter Margaret Kelly's re-structuring of the novel's disparate narrative strands, ${ }^{2}$ the theme of the circularity of middle-class existence is altered through Debbie and Sue's decision to leave the surfing gang. The protagonists' defiant decision to surf, an activity prohibited among girls at the time, can thus be viewed as an alternative to Garry's fate. To the extent that female surfers engage in second wave feminism's quest for equality for women, Debbie and Sue's defiance of the gang is a middle-class gesture, since the feminist movement was then predominantly white and middle-class. Indeed, it is likely that the boldness with which Debbie and Sue carry their surfboard onto Cronulla beach in the film's final scene is enabled by their privileged status as members of affluent local families (and former Greenhills girls). At the same time, the ignominy of their earlier status of 'dickheads' is echoed when their peers dub them 'Westies' and 'slack molls'. In Puberty Blues, the protagonists' progression from 'dickheads' to Greenhills girls and their subsequent defiance of the male domination of surfing suggests an open-ended quest to defy social constraints.

In Bruce Beresford's Puberty Blues, the Cronulla surf subculture serves as a prism through which Australian class identities are viewed. Consistent with Australian popular culture's shift away from class themes, the film's delineation of class is somewhat obscured by an emphasis on social identities that are defined by the surfing subculture. Yet links between Puberty Blues and 1970s Australian cinema are evident in the bleak and satirical overtones of 
Beresford's depiction of the middle class. While Debbie and Sue's tendency to be dazzled by surfers is undermined when drugs intrude upon their world, one character's flight from his parents' expectations implies that the comforts of suburbia are also deceptive. Expanding on earlier film representations of social difference, Puberty Blues broadens the depiction of class in Australian screen culture and explores with empathy contradictions in the lives of middleclass teenagers. Although the majority of Australian films made in the last twenty-five years are about the middle class, this social group is rarely addressed in analysis of Australian cinema. Equally, the plentiful literature about youth subcultures includes little work on Australian films. This article has addressed these areas of Australian cultural studies because middle-class identity and youth cultures are such prominent aspects of Australian life as to be crucially important, even as their omnipresence means they are easily overlooked. 


\section{ENDNOTES}

${ }^{1}$ Puberty Blues' depiction of teenage sex also has parallels with a contemporaneous proliferation of American teen sex comedies. For instance, Nell Schofield notes that both Puberty Blues and Amy Heckerling's Fast Times at Ridgemont High (1982, USA) were altered to meet the legal requirement that cast members be at least sixteen years of age (2004, p. 20). Both films can be considered daring for addressing such controversial themes as teenage female sexuality, underage sex and unplanned pregnancy, at a time when most sex comedies centred on male characters. Like many American films of the same period, Puberty Blues was also squarely targeted to teenage audiences (Schofield, 2004, 20).

${ }^{2}$ In the novel Garry doesn't die, no Greenhills surfer overdoses (until the postscript), Debbie is impregnated by another boy and the surfers' funeral takes place at an earlier stage for an unnamed surfer who drowned. The screenplay's re-structuring of the narrative draws these disparate narrative strands together to create a climax that revolves more closely around problems in Debbie's relationship with the Greenhills gang.

\section{REFERENCES}

Cohen, Phil (1997) Subcultural conflict and working-class community, in Ken Gelder and Sarah Thornton (eds), The Subcultures Reader. London and New York: Routledge, pp. 90-99.

Dermody, Susan, and Jacka, Elizabeth (1988) The Screening of Australia: Anatomy of a National Cinema Volume 2. Sydney: Currency. 
Ehrenreich, Barbara (1990) Fear of Falling: The Inner Life of the Middle Class. New York: HarperCollins.

Ellis, Bob (1981) Episodes of vaginal vaudeville, The Review 18 December (p. unknown).

Erikson, Erik H (1974) Identity: Youth and Crisis. London: Faber \& Faber.

Fiske, John, Hodge, Bob, and Turner, Graeme (1987) Myths of Oz: Reading Australian Popular Culture. Sydney: Allen and Unwin.

Fussell, Paul (1983) Class: A Guide Through the American Status System. New York: Simon and Schuster.

Greer, Germaine (2002) Foreword, in Kathy Lette and Gabrielle Carey, Puberty Blues. Sydney: Pan Macmillan, pp. xi-xiii.

Lette, Kathy, and Carey, Gabrielle (2002) Puberty Blues. Sydney: Pan Macmillan.

McFarlane, Brian (1987) Australian Cinema 1970-1985. Richmond: William Heinemann.

McGregor, Craig (1997) Class in Australia. Ringwood: Penguin.

Morris, Meaghan (1989) Fate and the Family Sedan, East-West Film Journal 4.1 (Dec.), pp. 113-134. 
Morris, Meaghan (1980) Personal relationships and sexuality, in Scott Murray (ed.), The New Australian Cinema. West Melbourne: Nelson, pp. 133-151.

Mulvey, Laura (1989) Visual and Other Pleasures. Bloomington and Indiana: Indiana University Press.

O’Regan, Tom (1996) Australian National Cinema. London and New York: Routledge.

Schofield, Nell (2004) Puberty Blues. Sydney: Currency.

Speed, Lesley (2004) You and Me Against the World: Revisiting Puberty Blues, Metro 140, pp. 54-60.

Stratton, David (1990) The Avocado Plantation: Boom and Bust in the Australian Film

Industry. Sydney: Pan Macmillan.

Thornton, Sarah (1997) General Introduction, in Ken Gelder and Sarah Thornton (eds), The Subcultures Reader. London and New York: Routledge, pp. 1-7.

\section{FILMOGRAPHY}

The Big Steal (1990), Nadia Tass

Dating the Enemy (1996), Megan Simpson Huberman

Don's Party (1976), Bruce Beresford 
Fast Times at Ridgemont High (1982), Amy Heckerling

The FJ Holden (1977), Michael Thornhill

Hard Knocks (1980), Don McLennan

Looking for Alibrandi (2000), Kate Woods

Me Myself I (1999), Pip Karmel

Mouth to Mouth (1978), John Duigan

Muriel's Wedding (1994), P. J. Hogan

Puberty Blues (1981), Bruce Beresford

The Wog Boy (2000), Aleksi Vellis

\section{WEBSITES}

Fiske, John (1983) Surfalism and Sandiotics: The Beach in Oz Culture, Australian Journal of Cultural Studies 1.2 (September), pp. 120-148, viewed 31 October 2003, $<$ http://wwwmcc.murdoch.edu.au/ReadingRoom/serial/AJCS/1.2/Fiske.html>. 
